\title{
Hemşirelerin Fiziksel Tespite Yönelik Bilgi Düzeyi, Tutum ve Uygulamalarının Değerlendirilmesi
}

\author{
Ümmügülsüm Gülø, Funda Kavak@
}

İnönü Üniversitesi, Hemşirelik Fakültesi, Malatya, Türkiye

Ümmügülsüm Gül, Doktora Öğrencisi Funda Kavak, Dr. Öğr. Üyesi

*Bu araştırma Ocak 2018 tarihinde yüksek lisans tezi olarak kabul edilmiştir.

İletişim:

Dr. Öğr. Üyesi Funda Kavak

İnönü Üniversitesi, Hemşirelik, Malatya, Türkiye Tel: +905348286810

E-Posta: funda-kavak@hotmail.com

Gönderilme Tarihi : 22 Mayıs 2018

Revizyon Tarihi : 30 Mayıs 2018

Kabul Tarihi : 30 Mayıs 2018
ÖZET

Amaç: Bu araştırma hemşirelerin fiziksel tespite yönelik bilgi düzeyi, tutum ve uygulamalarını değerlendirmek amacıyla yapılmıştır.

Gereç ve yöntem: Araştırma Ekim 2017-Aralık 2017 tarihleri arasında tanımlayıcı olarak yapıımıştır. Araştırmanın evrenini Malatya Turgut Özal Tıp Merkezi'nde çalışan hemşireler oluşturmuştur. Araştırma 320 hemşire ile tamamlanmıştır. Verilerin toplanmasında "Tanıtıı Özellikler Formu" ve "Fiziksel Tespit Edici Kullanımına İlişkin Bilgi Düzeyi, Tutum ve Uygulamaları Ölçeği" kullanıımıştır.

Bulgular: Araştırmada fiziksel tespite yönelik bilgi düzeyi ortalaması $2.56 \pm 1.56$, tutum ortalaması $28.82 \pm 5.02$, uygulama ortalaması $21.58 \pm 3.42$ olarak bulunmuştur. Psikiyatri servislerinde çalışan hemşirelerin diğer servis hemşirelerine oranla fiziksel tespite yönelik bilgi düzeyinin daha yüksek, tutumların daha olumlu ve uygulamaların daha yüksek olduğu saptanmıştır.

Sonuçlar: Araştırmada hemşirelerin fiziksel tespite yönelik bilgi düzeylerinin düşük, tutumlarının olumlu ve uygulamalarının düşük olduğu bulunmuştur.

Anahtar sözcükler: Fiziksel tespit, hemşire

IDENTIFICATION OF NURSES' KNOWLEDGE, ATTITUDES AND PRACTICES REGARDING THE USE OF PHYSICAL RESTRAINT

\section{ABSTRACT}

Purpose: This study was conducted to evaluate the level of knowledge, attitudes and practices of nurses towards physical restraint.

Methods: The study was conducted as a descriptive study between 0ctober 2017 and December 2017. Nurses working in Malatya Turgut Ozal Medical Center created/formed the universe of the research. The study was completed with 320 nurses. In the collection of data, "Introductory Characteristics Form" and "Level of Knowledge, Attitude and Practices for Using Physical Restraint" were used.

Results: The average level of knowledge is $2.56 \pm 1.56$, attitude average is $28.82 \pm 5.02$, and application average about the use of physical restraint in the study is $21.58 \pm 3.42$. The level of knowledge about using physical restraint in psychiatric services is higher, attitudes are more positive and applications are higher than other services.

Conclusions: In the study, it was found that the knowledge level of nurses for physical restraint was low, attitudes were positive and applications were low.

Keywords: Physical restraint, nurse 
$\mathbf{T}$ espit yöntemleri; iletişim tespiti, fiziksel tespit ve kimyasal tespit olmak üzere üç çeşittir. Tercih edilen kısıtlama türü iletişim yöntemi iken bizde kimyasal yöntem fiziksel yöntemlerden de daha çok kullanıldığını söyleyebiliriz. Hastanelerde fiziksel tespit uygulaması; hastaların yataktan düşmesini engellemek, tüplerini ve kateterlerini çıkarmasını önlemek, ajitasyon nedeniyle kendisine ya da çevresine zarar vermesini engellemek, yatağa bağımlı hastaların vücut postürlerini korumak ve sağlık personelinin tıbbi tedavi yapmasına olanak sağlamak amacıyla kullanılmaktadır (1-4).

Psikiyatri kliniklerinde hastaların saldırgan davranışlarını engellemek amacıyla fiziksel tespit uygulanmaktadır (5). Hemşireler psikiyatri kliniğinde sıklıkla saldırgan hastalarla karşı karşıya gelmektedir (6). Psikiyatri kliniklerinde sağlık personeline, diğer hastalara yönelik tehlike teşkil eden davranışları engellemeye ve güvenlik amacı ile fiziksel tespit yöntemleri diğer kliniklere göre daha fazla kullanmak zorunda kalınabilmektedir (4-6). Fiziksel tespiti hastalar ceza yöntemi olarak değerlendirmektedir (7). Walkana ve ark. fiziksel tespite yönelik yaptığı çalışmada hastaların \% 66.3'ü fiziksel tespiti cezalandırıcı ve özgürlüklerini kaybettikleri bir yöntem olarak ifade etmişlerdir. Hastaların tespit deneyimleri sorgulandığında tespit sırasında temel ihtiyaçların karşılanmadığı, personelin kendileriyle iletişime geçmediği, tespit sonrası takipte yetersizlik olduğunu savunmuşlardır (8).

Hastaların yapılan fiziksel tespit işleminin bir cezalandırma şekli değil de tedavisine yardımcı bir yöntem olarak değerlendirmesi açısından uygulama esnasında hasta ile işbirliği yapabilmek için ve bu işlemin ne amaçla yapıldığı hakkında sağlık çalışanları ve hastaların bilgilendirilmesi gerekmektedir (9).

Yoğun bakım ünitelerinde fiziksel kısıtlama kullanımına ilişkin yapılan çalışmalarda; fiziksel kısıtlama uygulamasının Amerika'da \%39, Kanada'da \%53 oranında kullanıldığı belirtilmiştir. Türkiye'de ise bu oran \%90.5 ile \%96.1 arasında değişmekte olduğunu belirten kaynaklar bulunmaktadır (10-13).

Bir acil serviste çalışan sağlık çalışanlarında yapılan bir çalışmada; katılımcıların \%50'si hastaya tespit edici uygulandığında kendini suçlu hissettiğini, \%68.3'ü tespit uygulamasının hemşirelik bakım süresini kısalttığını belirtmektedir (14).

Yoğun bakımda yapılan bir çalışmada hemşirelerin fiziksel tespite yönelik bilgilerinin oldukça iyi düzeyde olduğu ve tutumlarının da olumlu olduğu belirlenmiştir. Ancak hemşirelerin fiziksel tespit uygulamalarında bazı eksikliklerin olduğu saptanmıştır. Hemşirelerin fiziksel tespiti hekim istemi ile uygulamadıkları ve tespit edicinin doğru pozisyonda olduğunu 2 saatte bir kontrol etme uygulamasını hiç dikkate almadıkları saptanmıştır (15).

Fiziksel tespite yönelik etik ikilemler günümüzde hala devam etmektedir. Uluslararası önerilere rağmen tespit özellikle psikiyatri uygulamasının rutin parçası olarak işlev görmektedir. Hastanelerdeki personel ve hasta yaralanmalarının çoğu, fiziksel tespit süreci içerisinde gerçekleşmektedir (16). Avrupa Konseyi'nden çıkan yeni öneriler, fiziksel tespit kullanım yararının, bunu gerekli kılan risklerle orantılı olması gereğini belirtir ve kullanımları yasaklanmamıştır (17). Fakat konsey fiziksel tespit uygulanmadan önce alternatif yöntemlerin denenmesini ve tespitin bir doktor gözetiminde kullanılması gerektiği vurgulamıştır (18).

Ülkemizde konu ile ilgili çalışmalar sınırlı sayıdadır ve araştırmanın yapıldığı bölgede hastaların ve personelin tespit deneyimleri ve tutumlarıyla ilgili herhangi bir çalışmaya rastlanılmamıştır. Araştırmanın sonucunda elde edilecek verilerin yapılacak diğer çalışmalara yol gösterecek nitelikte olabileceği düşünülmektedir.

Bu araştırma hemşirelerin fiziksel tespite yönelik bilgi düzeyi, tutum ve uygulamalarını değerlendirmek amacıyla yapılmıştır.

\section{Gereç ve yöntem}

Araştırmanıntipi

Araştırma tanımlayıcı olarak yapılmıştır.

\section{Araştırmanın evren ve örneklemi}

Araştırmanın evrenini doğuda bir Üniversite Hastanesi'nde çalışan hemşireler oluşturmuştur. Üniversite Hastanesi'nde çalışan toplam 850 hemşire bulunmaktadır. Araştırmada örneklem seçimine gidilmeden en az bir defa fiziksel tespit uygulayan ve araştırmaya katılmayı kabul eden hemşireler araştırmaya dahil edilmiştir. Araştırma 320 hemşire ile tamamlanmıştır.

\section{Verilerin toplanması}

Veriler Ekim 2017-Aralık 2017 tarihleri arasında Üniversite Hastanesi'nde toplanmıştır. Araştırmanın verilerini toplamak için Tanıtıcı Özellikler Formu, Fiziksel Tespit Edici Kullanımına İlişkin Bilgi Düzeyi, Tutum ve Uygulamalar Ölçeği kullanılmıştır. Veri toplama formları hemşirelere 
hastanede uygun zamanlarda araştırmacı tarafından uygulanmıştır. Formları hemşireler kendileri doldurmuştur. Veri toplama formunun uygulanma süresi ortalama 15-20 dk sürmüştür.

\section{Veri toplama araçları}

Tanıtıcı özellikler formu

Tanıtıcı Özellikler Formu araştırmacılar tarafından literatür taranarak oluşturulan katılımcıların tanıtıcı özelliklerini içeren 7 sorudan (yaş, cinsiyet, eğitim durumu, medeni durum, hizmet süresi, çalışma şekli, çalışılan servis) oluşmaktadır.

Hemşirelerin fiziksel tespit edici kullanımına ilişkin bilgi düzeyi, tutum ve uygulamaları ölçeği

Suen tarafından 1999 yılında geliştirilen Ölçeğin Türkçe geçerlilik ve güvenilirliği Kaya ve arkadaşları tarafından 2008 yılında yapılmıştır. Ölçeğin Cronbach's Alpha değeri 0.88-0.90 arasında değişmektedir. Ölçek bilgi düzeyi (0-11 puan), tutum (12-48 puan) ve uygulamalar (14-42 puan) olmak üzere üç bölümden oluşmaktadır (19). Ölçekten alınan puanlar arttıkça bilgi düzeyi artmakta, tutum olumlu hale gelmekte ve uygulamalar iyileşmektedir. Araştırmada ölçeğin cronbach alpha kat sayısı 0.89 olarak bulunmuştur.

\section{Verilerin değerlendirilmesi}

Araştırma verileri SPSS 22.0 programında değerlendirilmiştir. Ölçümle belirtilen verilerin değerlendirmesinde tanımlayıcı istatistiksel yöntemlerin (frekans, ortalama, standart sapma) yanı sıra, parametrik test varsayımları karşılandığı için iki grubun karşılaştırılmasında bağımsız $t$-testi ve ANOVA uygulanmıştır. Sürekli değişkenler arasındaki ilişki için Pearson korelasyon analizi, nitel verilerin karşılaştııılmasında ki-kare testi kullanılmıştır. Sonuçlar $p<.05$ anlamlılık düzeyinde değerlendirilmiştir.

\section{Araştırmanın etik yönü}

Araştırmaya başlamadan önce İnönü Üniversitesi Sağlık Bilimleri Girişimsel Olmayan Etik Kuruldan onay ve araştırmanın yapılacağı kurumdan izin alınmıştır. Hemşirelerin anlamadığı sorulara yorum katılmadan açıklama yapılmıştır ve araştırmadan istedikleri zaman ayrılma hakkı oldukları açıklanmıştır.

\section{Bulgular}

Araştırmaya katılan hemşirelerin \%53.8'inin 29-39 yaş aralığında, \%72.8'inin kadın, \%60.0'ının evli, \%70'inin lisans mezunu olduğu, \%36.3'ünün 10 yıl ve üzeri, \%38.8'inin yoğun bakımda, \%65.0'inin gündüz+vardiya olarak çalıştığı belirlenmiştir (Tablo 1).
Tablo 1. Hemşirelerin tanıtıcı özellikleri $(n=320)$

\begin{tabular}{|c|c|c|}
\hline Tanıtıcı Özellikler & $n$ & $\%$ \\
\hline \multicolumn{3}{|l|}{ Yaş } \\
\hline $18-28$ & 117 & 36.6 \\
\hline 29-39 & 172 & 53.8 \\
\hline $40-50$ & 31 & 9.7 \\
\hline \multicolumn{3}{|l|}{ Cinsiyet } \\
\hline Kadın & 233 & 72.8 \\
\hline Erkek & 87 & 27.2 \\
\hline \multicolumn{3}{|l|}{ Medeni Durum } \\
\hline Evli & 192 & 60.0 \\
\hline Bekar & 128 & 40.0 \\
\hline \multicolumn{3}{|l|}{ Eğitim Durumu } \\
\hline Lise & 21 & 6.6 \\
\hline Ön Lisans & 45 & 14.1 \\
\hline Lisans & 224 & 70.0 \\
\hline Yüksek Lisans ve Doktora & 30 & 9.4 \\
\hline \multicolumn{3}{|l|}{ Hizmet Süresi } \\
\hline 1 yıldan az & 31 & 9.7 \\
\hline $2-5 \mathrm{yll}$ & 87 & 27.2 \\
\hline $6-9$ yıl & 86 & 26.9 \\
\hline 10 yıl ve üzeri & 116 & 36.3 \\
\hline \multicolumn{3}{|l|}{ Çalışılan Birim } \\
\hline Dahili Birim & 85 & 26.6 \\
\hline Cerrahi Birim & 80 & 25.0 \\
\hline Psikiyatri & 31 & 9.7 \\
\hline Yoğun Bakım & 124 & 38.8 \\
\hline \multicolumn{3}{|l|}{ Calıșma Sekli } \\
\hline Gündüz & 91 & 28.4 \\
\hline Gündüz+vardiya & 208 & 65.0 \\
\hline Vardiya & 21 & 6.6 \\
\hline
\end{tabular}

Araştırmada hemşirelerin fiziksel tespit edici kullanımına ilişkin bilgi düzeylerinin ortalaması $2.56 \pm 1.56$, tutum düzeylerinin ortalaması $28.82 \pm 5.02$, uygulama düzeylerinin ortalaması $21.58 \pm 3.42$ olarak bulunmuştur. Hemşirelerin fiziksel tespite yönelik bilgi düzeylerinin düşük, tutumlarının olumlu, uygulamalarının orta düzeyde olduğu tespit edilmiştir (Tablo 2).

Tablo 2. Fiziksel tespit edici kullanımına ilişkin bilgi düzeyi, tutum ve uygulamalar ölçeğinin toplam puan ortalamaları

\begin{tabular}{lcc} 
& Minimum Maximum Puan & Ort $\pm S S$ \\
\hline Bilgi Düzeyi (0-11) & $0-9$ & $2.56 \pm 1.56$ \\
Tutum (12-48) & $13-42$ & $28.82 \pm 5.02$ \\
Uygulama (14-42) & $16-42$ & $21.58 \pm 3.42$
\end{tabular}


Araştırmada hemşirelerin tanıtıcı özelliklerine göre fiziksel tespite yönelik bilgi düzeyleri incelendiğinde; cinsiyet ile bilgi düzeyi, çalışılan birim ile bilgi düzeyi, çalışma şekli ile bilgi düzeyi arasında bulunan fark istatistiksel olarak anlamlıdır $(p<.05)$. Erkeklerde, psikiyatri servisinde ve vardiya usulü ile çalışanlarda fiziksel tespite yönelik bilgi düzeyinin daha yüksek olduğu, saptanmıştır. Hemşirelerin tanıtıcı özelliklerine göre fiziksel tespite yönelik tutumları incelendiğinde; medeni durum ile tutum, hizmet süresi ile tutum, çalışılan birim ile tutum arasında istatistiksel olarak anlamlı bir fark bulunmuştur $(\mathrm{p}<.05)$.

Evlilerde, uzun süre hemşirelik yapanlarda ve yoğun bakımda çalışanlarda fiziksel tespite yönelik tutumların daha olumlu olduğu belirlenmiştir. Araştırmada hemşirelerin tanıtıcı özelliklerine göre fiziksel tespite yönelik uygulamaları incelendiğinde; cinsiyet ile uygulama, medeni durum ile uygulama, hizmet süresi ile uygulama, çaIışılan birim ile uygulama, çalışma şekli ile uygulama arasında bulunan fark istatistiksel olarak anlamlıdır $(p<.05$, Tablo 3). Erkeklerde, bekârlarda, mesleğe yeni başlayanlarda, psikiyatri servislerinde ve vardiya usulü ile çalışanlarda fiziksel tespite yönelik uygulamaların daha yüksek olduğu bulunmuştur.

\section{Araştırmanın sınırlılığı}

Araştırmanın sadece bir hastanede yürütülmesi ve düşük örneklem grubunda yapılması araştırmanın sınırlıı̆̆ıdır. Bu nedenle sonuçlar sadece bu gruba genellenebilir.

\section{Tartışma}

Hemşirelerin fiziksel tespite yönelik bilgi düzeyi, tutum ve uygulamalarını değerlendirmek amacıyla yapılan araştırmanın bulguları literatür doğrultusunda tartışılmıştır.

Araştırmada hemşirelerin fiziksel tespite yönelik bilgi düzeyi ölçek toplam puan ortalamasından alınabilecek puanlar dikkate alındığında; hemşirelerin bilgi düzeylerinin düşük olduğu belirlenmiştir. Orhan ve Yakut çocuk yoğun bakım hemşirelerinde yaptığı çalışmada hemşirelerin fiziksel tespit edici kullanımına ilişkin bilgi düzeyinin yüksek olduğu belirlenmiştir (20). Balcı yoğun bakımda çalışan hemşirelerde yaptığı çalışmada hemşirelerin fiziksel tespite yönelik bilgi düzeylerinin yüksek olduğu belirlenmiştir (21). Gürdoğan ve ark. yoğun bakımda çalışan hemşirelerin fiziksel tespite yönelik bilgi düzeylerinin yüksek olduğu tespit edilmiştir (22). Bakır ve ark. acil servislerde çalışan hemşirelerde yaptığı çalışmada bilgi düzeyinin yüksek olduğu belirlenmiştir çiftlerin romantik ilişkilerini ve eş seçimini olumlu yönde etkilediği
Tablo 3. Hemşirelerin tanıtıcı özelliklerine göre fiziksel tespit edici kullanımına ilişkin bilgi düzeyi, tutum ve uygulamalarının karşılaşııııması

\begin{tabular}{|c|c|c|c|c|c|}
\hline Tanıtıcı Özellikler & $n$ & $\%$ & Bilgi Düzeyi & Tutum & Uygulama \\
\hline \multicolumn{6}{|l|}{ Cinsiyet } \\
\hline Kadın & 233 & 72.8 & $2.42 \pm 1.54$ & $28.66 \pm 5.07$ & $21.30 \pm 2.93$ \\
\hline Erkek & 87 & 27.2 & $2.96 \pm 1.58$ & $29.22 \pm 4.90$ & $22.35 \pm 4.36$ \\
\hline Test Değeri & & & $\mathrm{t}=2.795$ & $t=0.886$ & $t=2.483$ \\
\hline Anlamlılık & & & $p=.006$ & $p=.376$ & $p=.014$ \\
\hline \multicolumn{6}{|l|}{ Medeni Durum } \\
\hline Evli & 192 & 60.0 & $2.57 \pm 1.58$ & $29.45 \pm 5.07$ & $21.18 \pm 2.93$ \\
\hline Bekâr & 128 & 40.0 & $2.55 \pm 1.55$ & $27.86 \pm 4.81$ & $22.18 \pm 3.95$ \\
\hline Test Değeri & & & $\mathrm{t}=0.131$ & $t=2.802$ & $t=2.591$ \\
\hline Anlamlillk & & & $p=.896$ & $p=.004$ & $p=.010$ \\
\hline \multicolumn{6}{|l|}{ Hizmet Süresi } \\
\hline 1 yıldan az & 31 & 9.7 & $2.38 \pm 1.58$ & $27.54 \pm 4.23$ & $22.09 \pm 3.44$ \\
\hline $2-5 \mathrm{yll}$ & 87 & 27.2 & $2.51 \pm 1.29$ & $27.82 \pm 4.61$ & $22.13 \pm 4.38$ \\
\hline $6-9 \mathrm{yll}$ & 86 & 26.9 & $2.77 \pm 1.85$ & $28.88 \pm 4.66$ & $22.01 \pm 3.04$ \\
\hline 10 yıl ve üzeri & 116 & 36.3 & $2.50 \pm 1.52$ & $29.68 \pm 5.22$ & $20.72 \pm 2.59$ \\
\hline Test Değeri & & & $F=0.758$ & $\mathrm{~F}=4.014$ & $F=3.188$ \\
\hline Anlamlilık & & & $p=.334$ & $p=.003$ & $p=.024$ \\
\hline \multicolumn{6}{|l|}{ Çalışılan Birim } \\
\hline Dahili Birim & 85 & 26.6 & $2.75 \pm 1.94$ & $28.38 \pm 4.36$ & $21.71 \pm 3.08$ \\
\hline Cerrahi Birim & 80 & 25.0 & $2.27 \pm 1.20$ & $27.88 \pm 5.06$ & $20.57 \pm 2.62$ \\
\hline Psikiyatri & 31 & 9.7 & $2.70 \pm 1.39$ & $29.51 \pm 6.77$ & $22.32 \pm 4.55$ \\
\hline Yoğun Bakım & 124 & 38.8 & $2.59 \pm 1.51$ & $29.54 \pm 4.44$ & $21.96 \pm 3.64$ \\
\hline Test Değeri & & & $F=1.429$ & $F=2.216$ & $F=3.461$ \\
\hline Anlamlilık & & & $p=.020$ & $p=.031$ & $p=.017$ \\
\hline \multicolumn{6}{|l|}{ Çalışma Şekli } \\
\hline Gündüz & 91 & 28.4 & $2.12 \pm 1.41$ & $29.37 \pm 5.45$ & $20.75 \pm 3.13$ \\
\hline Gündüz+vardiya & 208 & 65.0 & $2.69 \pm 1.56$ & $28.78 \pm 4.67$ & $21.81 \pm 3.50$ \\
\hline Vardiya & 21 & 6.6 & $3.28 \pm 1.79$ & $26.76 \pm 6.12$ & $23.04 \pm 2.85$ \\
\hline Test Değeri & & & $K W=10.289$ & $\mathrm{KW}=4.385$ & $K W=15.481$ \\
\hline Anlamlılık & & & $p=.006$ & $p=.112$ & $p=.000$ \\
\hline
\end{tabular}

saptanmışıı ${ }^{5}$. Araştırmanın sonuçları literatürle paralellik göstermektedir. Kaya ve ark. yoğun bakım, acil ve psikiyatride çalışan hemşirelerde yapmış olduğu çalışmada fiziksel tespite yönelik bilgi düzeylerinin yüksek olduğu saptanmıştır (19). Araştırmaya hastanede çalışan tüm hemşireler dahil edilmiştir. Fakat literatürde yapılan diğer araştırmalara bakıldığında özellikle yoğun bakım, acil, psikiyatri servisinde çalışan hemşireler çalışmalara alınmıştır. Yoğun bakım, acil ve psikiyatri servislerinde fiziksel tespit edicilerin kullanımının daha yaygın olması, bu nedenle fiziksel tespit öncesi hemşirelere eğitim verilmesi hemşirelerin bilgi düzeylerinin yüksek olma nedeni olarak düşünülebilir $(21,23)$. 
Araştırmaya katılan hemşirelerin fiziksel tespite yönelik tutum ölçek toplam puan ortalamasından alınabilecek puanlar dikkate alındığında; hemşirelerin tutumlarının olumlu olduğu belirlenmiştir. Çelik ve ark. yoğun bakımda çalışan hemşirelerde yapmış olduğu çalışmada hemşirelerin fiziksel tespite yönelik tutumlarının olumlu olduğu belirlenmiştir (15). Orhan ve Yakut çocuk yoğun bakım hemşirelerinde yaptığı çalışmada hemşirelerin fiziksel tespite yönelik tutumlarının olumlu olduğu tespit edilmiştir (20). Gürdoğan ve ark. yoğun bakımda çalışan hemşirelerde yapmış olduğu çalışmada hemşirelerin fiziksel tespite yönelik tutumlarının olumlu olduğu belirlenmiştir (22). Bakır ve ark. acil servislerde yaptığı çalışmada hemşirelerin fiziksel tespite yönelik tutumlarının olumlu olduğu tespit edilmiştir (14). Kaya ve ark. yoğun bakım, acil ve psikiyatride çalışan hemşirelerde yapmış olduğu çalışmada hemşirelerin fiziksel tespite yönelik tutumlarının olumlu olduğu bulunmuştur (19). Araştırmanın sonuçları literatürle paralellik göstermektedir. Hemşirelerin fiziksel tespit uygulamasını hastaya yarar sağlamak amacıyla yaptığı ve fiziksel tespiti uygularken etik ilkelere dikkat etmesi, hastalarla empati kurması bu sonucun nedeni olarak düşünülebilir.

Araştırmada hemşirelerin fiziksel tespite yönelik uygulama ölçek toplam puan ortalamasından alınabilecek puanlar dikkate alındığında; hemşirelerin uygulama düzeylerinin orta olduğu belirlenmiştir. Orhan ve Yakut çocuk yoğun bakım hemşirelerinde yaptığı çalışmada hemşirelerin fiziksel tespit uygulamalarının yüksek olduğu tespit edilmiştir (20). Çelik ve ark. yoğun bakımda çalışan hemşirelerde yapmış olduğu çalışmada hemşirelerin fiziksel tespit uygulamalarının yüksek olduğu belirlenmiştir (15). Kaya ve ark. yoğun bakım, acil, psikiyatri servisinde çalışan hemşirelerde yaptığı çalışmada hemşirelerin fiziksel tespit uygulamasının yüksek olduğu bulunmuştur (19). Yoğun bakım, acil ve psikiyatri servislerinde diğer servislere oranla hastalarda daha çok deliryum tablosu, düşme, saldırganlık, sinirlilik, bilinç bulanıklığı ya da kaybı görülmektedir. Sağlık çalışanları hem kendilerini korumak hem de hastaları korumak için hasta yararına karar verip fiziksel tespit ediciler kullanmaktadır $(1,2)$. Bu araştırmada dahili ve cerrahi kliniklerde çalışan hemşirelerin sayısı daha fazla olduğu için fiziksel tespit uygulamasının ortalamasının azaldığı söylenebilir.

Araştırmada hemşirelerin tanıtıcı özelliklerine göre fiziksel tespit edici kullanımına ilişkin bilgi düzeyleri incelendiğinde; cinsiyet, çalışılan birim ve çalışma şekli ile bilgi düzeyi arasındaki fark istatistiksel olarak anlamlı bulunmuştur $(p<.05)$. Erkeklerde, psikiyatri servisinde ve vardiya usulü ile çalışanlarda fiziksel tespite yönelik bilgi düzeyinin daha yüksek olduğu saptanmıştır. Balcı yaptığı çalışmada hemşirelerde cinsiyetin fiziksel tespite yönelik bilgi düzeyini etkilemediği bulunmuştur (21). Orhan ve Yakut yapmış olduğu çalışmada erkek hemşirelerin kadınlara oranla fiziksel tespite yönelik bilgi düzeylerinin daha yüksek olduğu belirlenmiştir (20). Araştırmaya katılan erkek hemşirelerin sayısının az olması bu sonucun nedeni olarak düşünülebilir. Psikiyatri servisindeki hastalarda fiziksel tespit uygulamalarının diğer kliniklere oranla daha fazla olması hemşirelere eğitim verilmesini gerektirmektedir. Buna bağlı olarak psikiyatri servisinde çalışan hemşirelerde fiziksel tespite yönelik bilgi düzeyinin yüksek olması beklenmektedir. Vardiya usulü ile çalışan hemşirelerde fiziksel tespite yönelik bilgi düzeyinin yüksek olma nedeni olarak gece nöbetlerinde hastaların daha çok saldırganlık göstermesi ve deliryum belirtilerinin artması söylenebilir $(15,16)$.

Araştırmaya katılan hemşirelerin tanıtıcı özelliklerine göre fiziksel tespit edici kullanımına ilişkin tutumları incelendiğinde; medeni durum, hizmet süresi ve çalışılan birim ile tutum arasında istatistiksel olarak anlamlı bir fark bulunmuştur ( $p<.05)$. Evlilerde, 10 yıl ve üzeri hemşirelik yapanlarda ve yoğun bakımda çalışanlarda fiziksel tespite yönelik tutumların daha olumlu olduğu belirlenmiştir. Çelik ve ark. yaptığı çalışmada yoğun bakım ünitesinde çalışan hemşirelerin tutumlarının diğer servislere kıyasla daha olumlu olduğu belirlenmiştir (15). Araştırmanın sonucu literatürle paralellik göstermektedir.

Araştırmada hemşirelerin tanıtıcı özelliklerine göre fiziksel tespit edici kullanımına ilişkin uygulamaları incelendiğinde; cinsiyet, medeni durum, hizmet süresi, çalışılan birim ve çalışma şekli ile uygulama arasında bulunan fark istatistiksel olarak anlamlıdır ( $p<.05)$. Erkeklerde, bekârlarda, mesleğe yeni başlayanlarda, psikiyatri servislerinde ve vardiya usulü ile çalışanlarda fiziksel tespite yönelik uygulama puanlarının daha yüksek olduğu bulunmuştur. Kaya ve ark. yaptığı çalışmada psikiyatri kliniğinde diğer kliniklere göre fiziksel tespit uygulamaların daha fazla olduğu bulunmuştur (19). Coşkun ve ark. hemşirelerde yapmış olduğu çalışmada vardiya usulü çalışanlarda fiziksel tespitin daha fazla kullanıldığı bulunmuştur (24). Ucun ve ark. psikiyatri servislerinde çalışan hemşirelerde yapmış olduğu çalışmada gece vardiyasında hemşirelerin fiziksel tespite yönelik uygulamalarında artış olduğu belirlenmiştir (25). Araştırmanın sonuçları literatürle benzerlik göstermektedir

\section{Sonuç}

Hemşirelerin fiziksel tespite yönelik bilgi düzeyleri, tutum ve uygulamalarını değerlendirmek amacıyla yapılan 
bu araştırmada, hemşirelerin bilgi düzeylerinin düşük olduğu, fiziksel tespit edici kullanımına ilişkin tutumlarının olumlu olduğu, fiziksel tespit edici kullanımına ilişkin uygulamalarının düşük olduğu bulunmuştur. Bu sonuçlar doğrultusunda; fiziksel tespite yönelik hemşirelerin bilgi,

\section{Kaynaklar}

1. Cotter VT. Restraint free care in older adults with dementia. Keio J Med 2005;54:80-4. [CrossRef]

2. Sullivan-Marx EM. Achieving restraint-free care of acutely confused older adults. J Gerontol Nurs 2001;12:56-61. [CrossRef]

3. Yönt GH, Korhan EA, Dizer B, Gümüş F, Koyuncu R. Examination of ethical dilemmas experienced by adult intensive care unit nurses in physical restraint practices. Holist Nurs Pract 2014;12:85-90. [CrossRef]

4. Cheung PPY, Yam BMC. Patient autonomy in physical restraint. J Clin Nurs 2005;25:34-40. [CrossRef]

5. Busch $A B$, Shore MF. Seclusion and restraint: $A$ review of recent literature. Harv Rev Psychiatry 2000;12:261-70. [CrossRef]

6. Petit JR. Management of the acutely violent patient. Psychiatr Clin North Am 2005;13:701-11. [CrossRef]

7. Presley $D$, Robinson $G$. Violence in the emergency department: nurses contend with prevention in the health care arena. Nurs Clin North Am 2002;14:161-9. [CrossRef]

8. Keski-Valkama A, Sailas E, Eronen M, Koivisto AM, Kaltiala-Heino R. The reasons for using restraint and seclusion in psychiatric inpatient care: a nationwide 15-year study. Nord J Psychiatry 2010;64:136-44. [CrossRef]

9. Dilbaz N. Şiddet riskinin değerlendirilmesi ve saldırgan hastaya yaklaşım. Klinik Psikiyatri 1999;2:179-88.

10. Martin B, Mathisen L. Use of physical restraints in adult critical care: a bicultural study. Am J Crit Care 2005;14:133-42.

11. Luk E, Sneyers B, Rose L, Perreault MM, Williamson DR, Mehta S, et al. Predictors of physical restraint use in Canadian intensive care units. Crit Care 2014;18:R46. [CrossRef]

12. Demir A. Nurses' use of physical restraints in four Turkish hospitals. J Nurs Scholarsh 2007;39:38-45. [CrossRef]

13. Akansel N. Physical restraint practices among icu nurses in one university hospital in weastern turkey. Health Sci J 2007;4:16-22. Erişim: http://www.hs..gr/medicine/physical-restraint-practicesamong-icu-nurses-in-one-university-hospital-in-weastern-turkey. php?aid $=3675$

14. Bakır E, Şahin G, Dişel NR, Açıkalın Akpınar A. Adana İli Acil Serviste Çalışanların Fiziksel Tespit Kullanımına Iliş̧kin Bilgi Tutum ve uygulamaları. Zirve Tıp Derg 2016;10:6-10.

15. Çelik S, Kavrazıı S, Demircan E, Güven N, Durmuş Ö, Duran ES. Yoğun bakım hemşirelerinin fiziksel tespit kullanımına ilişkin bilgi, tutum ve uygulamaları. Acıbadem Üniv Sağlık Bil Derg 2012;3:176-83. Erişim: http://openaccess.acibadem.edu.tr:8080/xmlui/bitstream/ handle/11443/244/mak-3.pdf?sequence=1\&isAllowed $=y$ tutum düzeylerini arttırmak ve uygulamalarını olumlu hale getirmek amacıyla eğitimler planlanması, alternatif yöntemler oluşturulması, hemşirelerde fiziksel tespit kullanımını değerlendirmek için daha büyük örneklem gruplarıyla benzer çalışmaların yapılması önerilebilir.
16. Bilici R. Psikiyatri kliniklerinde tespit ve tecrit uygulamaları Bakırköy Ord. Prof. Mazhar Osman Ruh Sağlığı ve Sinir Hastalıkları Eğitim ve Araştırma Hastanesi 8. Psikiyatri Birimi, Yayınlanmamış Uzmanlık Tezi. İstanbul; 2007.

17. Mohr WK, Petti TA, Mohr BD. Adverse effects associated with physical restraint. Can J Psychiatry 2003;48:330-7. [CrossRef]

18. Kingdon $D$, Jones R, Lönnqvist J. Protecting the human rights of people with mental disorder: new recommendations emerging from the Council of Europe. Br J Psych 2004;185:277-9. [CrossRef]

19. Kaya H, Aştı T, Acaroğlu R, Erol S, Savcı C. Hemşirelerin fiziksel tespit edici kullanımına ilişkin bilgi, tutum ve uygulamaları. Maltepe Üniv Hem Bilim Sanat Derg 2008;1:21-9. Erişim: http://hemsirelik. maltepe.edu.tr/dergiler/cilt1 sayi2aralik2008/21_29.pdf

20. Orhan MF, Yakut Hí. Çocuk yoğun bakım hemşirelerinin fiziksel tespit edicilerin kullanımına ilişkin bilgi, tutum ve uygulama düzeylerinin belirlenmesi. Türkiye Çocuk Hast Derg 2012;4:155-60. Erişim: https:// dergipark.org.tr/download/article-file/688984

21. Balcı H. Yoğun Bakım Hemşirelerinin Fiziksel Tespit Edici Kullanımına Yönelik Bilgi, Tutum ve Uygulamaları. Sağlık Bilimleri Enstitüsü, Hemşirelik Anabilim Dalı. Yüksek Lisans Tezi. Konya: Selçuk Üniversitesi; 2016.

22. Gürdoğan EP, Uğur E, Kınıcı E, Aksoy B. Yoğun bakım hemşirelerinin fiziksel tespite ilişkin bilgi, tutum ve uygulamaları ve etkileyen faktörler. Yoğun Bakım Derg 2016;83-8. [CrossRef]

23. Karagözoğlu Ş, Özden D. Bir üniversite hastanesinde çalışan hemşirelerin fiziksel kısıtlamaya ilişkin bilgi ve uygulamaları. Hem Araş Geliş Derg (HEMAR-G) 2013;15:11-22. Erişim: http://hemarge. org.tr/ckfinder/userfiles/files/2013/makale_2.pdf

24. Coşkun S, Avlamaz F, Genç H. Akut psikoz kliniklerinde mekanik tespit uygulamasında cinsiyete özgü farklılıklar. Psikiyatri Hem Derg 2010;5:108-14. Erişim: http://www.journalagent.com/phd/pdfs/ PHD_1_3_108_114.pdf

25. Ucun $Y$, Gürhan N, Kaya B. Psikiyatri kliniğinde çalışan hemşirelerin ve hekimlerin hasta kısıtlama yöntemleri ile ilgili görüşleri. Hem Araş Geliş Derg (HEMAR-G) 2015; 17:10-20. Erişim: https://www. researchgate.net/publication/301350383_Psikiyatri_Kliniginde_ Calisan_Hemsirelerin_ve_Hekimlerin_Hasta_Kisitlama_Yontemleri_ ile_Ilgili_Gorusleri_Nurses's_and_Physicians'_Opinions_about_ Patient_Restraint_Methods_in_Psychiatry_Clinic 